Louisiana State University

LSU Digital Commons

2-14-2006

\title{
The structure of the carboxyltransferase component of acetyl- CoA carboxylase reveals a zinc-binding motif unique to the bacterial enzyme
}

\author{
Patrick Bilder \\ Vanderbilt University School of Medicine \\ Sandra Lightle \\ Pfizer Inc. \\ Graeme Bainbridge \\ Pfizer Inc. \\ Jeffrey Ohren \\ Pfizer Inc. \\ Barry Finzel \\ Pfizer Inc.
}

See next page for additional authors

Follow this and additional works at: https://digitalcommons.Isu.edu/biosci_pubs

\section{Recommended Citation}

Bilder, P., Lightle, S., Bainbridge, G., Ohren, J., Finzel, B., Sun, F., Holley, S., Al-Kassim, L., Spessard, C., Melnick, M., Newcomer, M., \& Waldrop, G. (2006). The structure of the carboxyltransferase component of acetyl-CoA carboxylase reveals a zinc-binding motif unique to the bacterial enzyme. Biochemistry, 45 (6), 1712-1722. https://doi.org/10.1021/bi0520479

This Article is brought to you for free and open access by the Department of Biological Sciences at LSU Digital Commons. It has been accepted for inclusion in Faculty Publications by an authorized administrator of LSU Digital Commons. For more information, please contact ir@lsu.edu. 


\section{Authors}

Patrick Bilder, Sandra Lightle, Graeme Bainbridge, Jeffrey Ohren, Barry Finzel, Fang Sun, Susan Holley, Loola Al-Kassim, Cindy Spessard, Michael Melnick, Marcia Newcomer, and Grover L. Waldrop 


\title{
The Structure of the Carboxyltransferase Component of Acetyl-CoA Carboxylase Reveals a Zinc-Binding Motif Unique to the Bacterial Enzyme ${ }^{\dagger,}$
}

\author{
Patrick Bilder,,$\stackrel{\S}{\S}$ Sandra Lightle, ${ }^{\perp, \|}$ Graeme Bainbridge, ${ }^{\perp}$ Jeffrey Ohren,${ }^{\perp}$ Barry Finzel,,${ }^{\perp}$ Fang Sun,${ }^{\perp}$ Susan Holley, ${ }^{\perp}$ \\ Loola Al-Kassim, ${ }^{\perp}$ Cindy Spessard, ${ }^{\perp}$ Michael Melnick, ${ }^{\perp}$ Marcia Newcomer, ${ }^{\#}$ and Grover L. Waldrop*,\# \\ Department of Biological Sciences, Louisiana State University, Baton Rouge, Louisiana 70803, Department of Biochemistry, \\ Vanderbilt University School of Medicine, Nashville, Tennessee 37232, and Pfizer Global Research and Development, \\ Ann Arbor, Michigan 48105
}

Received October 7, 2005; Revised Manuscript Received December 6, 2005

\begin{abstract}
Acetyl-coA carboxylase (ACC) is a central metabolic enzyme that catalyzes the committed step in fatty acid biosynthesis: biotin-dependent conversion of acetyl-coA to malonyl-coA. The bacterial carboxyltransferase (CT) subunit of ACC is a target for the design of novel therapeutics that combat severe, hospital-acquired infections resistant to the established classes of frontline antimicrobials. Here, we present the structures of the bacterial CT subunits from two prevalent nosocomial pathogens, Staphylococcus aureus and Escherichia coli, at a resolution of 2.0 and $3.0 \AA$, respectively. Both structures reveal a small, independent zinc-binding domain that lacks a complement in the primary sequence or structure of the eukaryotic homologue.
\end{abstract}

According to the Centers for Disease Control and Prevention, the rates of severe, multidrug-resistant bacterial infections, including those caused by pathogens previously confined to the hospital setting, have increased dramatically in both hospital and community populations $(1,2)$. Both Gram-positive [Staphylococcus aureus $(\mathrm{Sa})^{1}$ and Streptococcus pneumoniae] and Gram-negative [Escherichia coli $(E c)$ and Pseudomonas aeruginosa] bacteria have ultimately developed resistance to successive generations of clinically useful antibiotics. The severity of microbial resistance is underscored by the recent emergence of vancomycin-resistant clinical isolates of methicillin-resistant $S a$, which are responsible for most of the severe hospital-acquired illnesses $(3-5)$. The ability to combat these organisms will therefore require the development of pharmaceuticals against novel cellular targets $(6)$.

† This work was supported in part by the Louisiana Governor's Biotechnology Initiative.

The coordinates for the ACC carboxyltransferase subunits from $S$. aureus and E. coli have been deposited with the Protein Data Bank (PDB accession codes 2F9I and 2F9Y, respectively).

* To whom correspondence should be addressed: 206 Life Sciences Building, Baton Rouge, LA 70803. Telephone: 225-578-5209. Fax: 225-578-7258. E-mail: gwaldro@1su.edu.

$\S$ Vanderbilt University School of Medicine.

"These authors contributed equally to this work.

${ }^{\perp}$ Pfizer Global Research and Development.

\# Louisiana State University.

${ }^{1}$ Abbreviations: ACC, acetyl-CoA carboxylase; BCCP, biotinoyl carboxyl carrier protein; $\mathrm{BC}$, biotin carboxylase; CT, carboxyltransferase; PCC, propionyl-CoA carboxylase; ACP, acyl carrier protein; Ps 12S, Propionibacterium shermanii 12S transcarboxylase; Sa, Staphylococcus aureus; Ec, Escherichia coli; Sco, Streptomyces coelicolor; Sc, Saccharomyces cerevisiae; FAS II, bacterial type-II fatty acid biosynthesis; KAS, ketoacyl-ACP synthase; MMCoA, methyl-malonyl CoA; BiSA, bisubstrate analogue; HS, helical subdomain.
A subset of enzymes that catalyze bacterial type-II fatty acid biosynthesis (FAS II), a pathway distinct from the mammalian type-I system by virtue of its requirement for de novo fatty acid production and the structural divergence of its key constituents, represent strong candidates for antimicrobial drug design (7-9). Validation of the bacterial FAS II system as a potential pathway for the selection of novel targets is provided by anti-tubercular and broadspectrum antibacterial agents that selectively inhibit the enoyl-ACP (acyl carrier protein) reductase-mediated reduction step of the FAS II elongation cycle $(10-11)$. Additional FAS-II-pathway antimicrobials block $\beta$ ketoacyl-ACP synthase (KAS) enzymes responsible for fatty acid chain condensation (12-15). However, the design of enoyl-ACP reductase and KAS inhibitors across bacterial species is complicated by the presence of orthologous enzymes with multiple isoforms and/or variable substrate specificities (7). In contrast, the widespread conservation of bacterial acetylCoA carboxylase (ACC), an essential enzyme that generates the malonyl-CoA precursor required for the subsequent condensation steps of de novo fatty acid synthesis, suggests that ACC is an attractive FAS-II-pathway target. The potential for ACC as an antibiotic target is demonstrated by the recent discovery of the antibiotic Moiramide B and its derivatives, the pyrrolidinediones, as potent inhibitors of ACC $(16,17)$. Unfortunately, Moiramide B is not useful clinically. Other compounds, including several classes of well-established herbicides, the aryloxyphenoxypropionates and cyclohexanediones, and a synthetic bisubstrate analogue (BiSA) represent additional ACC-selective inhibitors (18, 19).

An assembly of protein constituents is required for in vivo ACC activity: biotinoyl carboxyl carrier protein (BCCP), 
biotin carboxylase (BC), and carboxyltransferase (CT). These components participate in the following partial reactions:

$$
\begin{aligned}
\mathrm{HCO}_{3}{ }^{-}+\mathrm{ATP}+ & \mathrm{BCCP}-\text { biotin } \stackrel{\mathrm{BC}, \mathrm{Mg}^{2+}}{\rightleftharpoons} \\
& \mathrm{BCCP}-\text { biotin }-\mathrm{CO}_{2}+\mathrm{ADP}+\mathrm{P}_{\mathrm{i}}
\end{aligned}
$$

$$
\begin{aligned}
& \text { BCCP-biotin }-\mathrm{CO}_{2}+\text { acetyl-CoA } \stackrel{\mathrm{CT}}{\rightleftarrows} \\
& \text { malonyl-CoA + biotin }
\end{aligned}
$$

The biotinylated mobile arm of BCCP shuttles the biotin cofactor from the site of BC-mediated, ATP-dependent carboxybiotin production (1) into the site of CT-mediated $\mathrm{CO}_{2}$ transfer from carboxybiotin to acetyl-CoA (2). In eubacteria, protozoa, and plant chloroplasts, ACC activity arises from a multisubunit assembly (prokaryotic ACC) of monomeric biotin- $\mathrm{BCCP}$, dimeric $\mathrm{BC}$, and heterotetrameric $\left(\alpha_{2} \beta_{2}\right)$ CT. In contrast, in fungi, animals, and plant cytosol, each of these subunits function as distinct domains within a single polypeptide (eukaryotic ACC) $(20,21)$. The two-step carboxylase reaction mechanism and the structural organization of the ACC multienzyme into distinct $\mathrm{BC}, \mathrm{BCCP}$, and CT components is shared among members of the biotindependent enzyme family, including propionyl-CoA carboxylase, transcarboxylase, glutaconyl-CoA decarboxylase, and methylcrotonyl-CoA carboxylase (22). The lack of primary sequence conservation observed between the prokaryotic and eukaryotic forms of ACC and the major differences in multi-enzyme subunit composition are features that can potentially be exploited to inhibit specific partial reactions of bacterial ACC without disruption of the mammalian homologue.

Herein, we present the X-ray structures of the CT component of bacterial ACC, a novel member of the crotonase superfamily, from representative Gram-positive $(S a)$ and Gram negative $(E c)$ species. Both structures possess a unique zinc-binding domain that partially shelters the acetyl-CoA binding site. This motif is conspicuously absent in both the primary sequence of the eukaryotic enzyme and the tertiary structure of the only eukaryotic ACC CT structure (yeast) reported to date (23).

\section{MATERIALS AND METHODS}

Cloning, Expression, and Purification. The strategy for overexpression of the genes coding for the $\alpha$ and $\beta$ subunits of $S a$ and $E c$ CT has been described by Blanchard and Waldrop (24). Because the genes for the $\alpha$ and $\beta$ subunits are not contiguous on the genome, a mini-operon was constructed to allow for overexpression of both genes. Specifically, the genes corresponding to the $\alpha$ (residues $1-314$ ) and $\beta$ (residues $1-285$ ) subunits of $S a$ CT were PCR-amplified from genomic DNA, ligated into pDESTT7-202, and transformed into E. coli strain BL21-Gold (DE3). After induction with $0.25 \mathrm{mM}$ IPTG, expression was carried out in a rich medium supplemented with $50 \mu \mathrm{g} / \mathrm{mL}$ kanamycin at $20^{\circ} \mathrm{C}$ for $20 \mathrm{~h}$. A similar cloning protocol was employed for the genes corresponding to the $\alpha$ (residues $1-319$ ) and $\beta$ (residues 1-304) of $E c$ CT, with the exception that the genomic amplification products were ligated into pET14b and transformed into strain BL21(DE3)pLysS. After induction with $3.2 \mathrm{mM}$ IPTG, expression of Ec CT was carried out in a rich medium supplemented with $100 \mu \mathrm{g} / \mathrm{mL}$ ampicillin and $34 \mu \mathrm{g} / \mathrm{mL}$ chloramphenicol at $20{ }^{\circ} \mathrm{C}$ for 15 h. In both cases, the cells were harvested by centrifugation at $6722 \mathrm{~g}$ for $30 \mathrm{~min}$ at $4{ }^{\circ} \mathrm{C}$. The pellets were lysed by freeze-thaw/resuspension in $50 \mathrm{mM}$ Tris-Base at $\mathrm{pH} 8.0$, $10 \mathrm{mM} \mathrm{MgCl} 2,500 \mathrm{mM} \mathrm{NaCl}$, and $1 \%$ Triton X-100 and passage through a microfluidizer. The lysate was centrifuged at $11000 \mathrm{~g}$ for $1 \mathrm{~h}$, and the supernatant was loaded onto a Ni-NTA resin (Qiagen) pre-equilibrated in $50 \mathrm{mM}$ Tris-Base at $\mathrm{pH} 8.0$ and $500 \mathrm{mM} \mathrm{NaCl}$ (buffer A). The CT subunits were eluted with a linear imidazole gradient from 0 to 200 $\mathrm{mM}$ in buffer A ( $\mathrm{Sa}$ CT) or in a step to $200 \mathrm{mM}$ imidazole after a $20 \mathrm{mM}$ imidazole wash (Ec CT). Eluted CT (assessed by SDS-PAGE) was dialyzed overnight in $10 \mathrm{mM} \mathrm{\textrm {KH } _ { 2 } -}$ $\mathrm{PO}_{4}$ at $\mathrm{pH} 7.0$ and $0.67 \mathrm{mM}$ EDTA, transferred for a second dialysis in $10 \mathrm{mM}$ HEPES at pH 7.0 and $500 \mathrm{mM} \mathrm{NaCl}$ the following day, and purified to homogeneity with a Hi-Load 26/60 Superdex 200 (Amersham) column pre-equilibrated with $25 \mathrm{mM}$ HEPES at $\mathrm{pH} 7.5$ and $500 \mathrm{mM} \mathrm{NaCl}$. In the case of $E c \mathrm{CT}$ only, the gel-filtration step was preceded by cleavage and removal of the His tag through thrombin (Sigma) digestion and passage over a Hi-Trap (Pharmacia) chelating column charged with $\mathrm{NiSO}_{4}$ in $25 \mathrm{mM}$ HEPES, $500 \mathrm{mM} \mathrm{NaCl}$, and $20 \mathrm{mM}$ imidazole at $\mathrm{pH}$ 7.5. The protein was subsequently concentrated to $15 \mathrm{mg} / \mathrm{mL}$ and stored in aliquots at $-80{ }^{\circ} \mathrm{C}$ prior to crystallization.

Crystallization. Sa CT or Ec CT (each at $15 \mathrm{mg} / \mathrm{mL}$ ) were cocrystallized with BiSA $(1 \mathrm{mM})$ under condition A $(30 \%$ PEG-400, 0.1 M HEPES at pH 8.0, and $0.2 \mathrm{M} \mathrm{MgCl}_{2}$ at 25 $\left.{ }^{\circ} \mathrm{C}\right)$ or condition B $\left(1 \mathrm{M} \mathrm{NaH}_{2} \mathrm{PO}_{4}, 1 \mathrm{M} \mathrm{K}_{2} \mathrm{HPO}_{4}, 0.2 \mathrm{M}\right.$ $\mathrm{Li}_{2} \mathrm{SO}_{4}$, and $0.1 \mathrm{M} \mathrm{CAPS}$ at $\mathrm{pH} 9.5$ and $4{ }^{\circ} \mathrm{C}$ ), respectively, by the vapor diffusion method. The $S a$ CT condition produced platelike crystals in 3-5 days. Hexagonal bipyramidal Ec CT crystals grew over a similar time interval under condition B.

$X$-ray Data Collection. Prior to data collection, CT crystals were flash-frozen in liquid nitrogen immediately after transfer to a solution of $10 \%$ ethylene glycol in mother liquor ( $\mathrm{Sa}$ $\mathrm{CT}$ ) or after slow, incremental transfer to $6.25,12.5$, and $25 \%$ ethylene glycol in reservoir solution $(E c \mathrm{CT})$. Complete data sets for $S a \mathrm{CT}$ and $E c$ CT were collected at $100 \mathrm{~K}$ to 1.98 and $3.2 \AA$, respectively, at the Industrial Macromolecular Crystallography Association Collaborative Access Team (IMCA-CAT) beam-line 17-ID at the Advanced Photon Source (Argonne National Laboratory). All data were processed with HKL2000 (38). Diffraction images were processed and scaled using the Denzo/HKL suite (37). Data collection statistics are shown in Table 1.

Structure Determination and Refinement. The structure of $\mathrm{Sa}$ CT was solved by molecular replacement in CNS (39) with a dimeric polyalanine search model derived from the Ps 12S hexamer (PDB ID 1ON3, chains A and D). A monomer of the search model corresponds to a tandem domain repeat, and each of the structurally homologous domains shares $<15 \%$ sequence identity with the $\alpha$ and $\beta$ subunits of $\mathrm{Sa} \mathrm{CT}$. The search model (the dimer that corresponds to a $\alpha_{2} \beta_{2}$ tetramer) was positioned in the asymmetric unit to give a correlation coefficient of two standard deviations above the mean. Placement of a single dimeric model is consistent with the noncrystallographic symmetry of the Patterson and a Matthew's coefficient $\left(V_{\mathrm{m}}\right.$ $=2.4 \AA^{3} / \mathrm{Da}$ ) in the generally observed range. After rigidbody, energy-minimization, and simulated-annealing refine- 


\begin{tabular}{|c|c|c|}
\hline & $\mathrm{SaCT}$ & $E c \mathrm{CT}$ \\
\hline \multicolumn{3}{|l|}{ data collection } \\
\hline resolution range $(\AA)$ & $50-1.98$ & $30-3.2$ \\
\hline total/unique reflections & $273345 / 90018$ & $183454 / 23565$ \\
\hline completeness (\%) & $98(82)^{a}$ & $100(100)$ \\
\hline redundancy & $3.0(2.7)$ & $7.8(8.0)$ \\
\hline$I / \sigma$ & $17.5(3.4)$ & $26.6(4.1)$ \\
\hline$R_{\text {merge }}(\%)^{b}$ & $6.0(29.3)$ & $6.8(41.2)$ \\
\hline \multicolumn{3}{|l|}{ refinement } \\
\hline resolution range $(\AA)$ & $50-1.98$ & $30-3.2$ \\
\hline number of reflections & 80987 & 22030 \\
\hline$\sigma$ cutoff & none & none \\
\hline$R$ factor $(\%)^{c}$ & 18.9 & 24.7 \\
\hline$R_{\text {free }}(\%)^{d}$ & 21.0 & 28.7 \\
\hline \multicolumn{3}{|l|}{ number of refined atoms } \\
\hline protein & 8689 & 4275 \\
\hline water & 583 & 7 \\
\hline \multirow{2}{*}{\multicolumn{3}{|c|}{ average $B$ factors $\left(\AA^{2}\right)$}} \\
\hline & & \\
\hline protein & 38.4 & 79.9 \\
\hline water & 42.8 & 44.6 \\
\hline $\mathrm{Zn}^{2+}$ & 40.1 & 78.6 \\
\hline overall & 38.7 & 79.8 \\
\hline $\begin{array}{l}B \text { from Wilson plot } \\
\text { rmsd }\end{array}$ & 31.7 & N/A \\
\hline bonds $(\AA)$ & 0.016 & 0.007 \\
\hline angles (deg) & 1.4 & 1.4 \\
\hline \multicolumn{3}{|l|}{ Ramachandran plot } \\
\hline most favorable & 91.2 & 75.5 \\
\hline additional allowed & 8.7 & 23.7 \\
\hline disallowed (\%) & 0.1 & $0.8^{e}$ \\
\hline
\end{tabular}

${ }^{a}$ Values in parentheses refer to the highest resolution shell. ${ }^{b} R_{\text {merge }}$ $=\sum_{h k l} \sum_{i}\left|I_{h k l}-\langle I\rangle_{h k l}\right| / \sum_{h k l} \sum_{i}\langle I\rangle_{h k l}$, where $I_{h k l}$ is the intensity measurement for a given reflection and $\langle I\rangle_{h k l}$ is the average intensity for multiple measurements of this reflection. ${ }^{c} R$ factor $=\sum\left|F_{\mathrm{o}, h k l}-F_{\mathrm{c}, h k l}\right| / \sum\left(F_{\mathrm{o}, h k l}\right)$ $\times 100$, where $F_{\mathrm{o}, h k l}$ is the observed structure factor amplitude and $F_{\mathrm{c}, h k l}$ is the calculated structure factor amplitude. ${ }^{d} R_{\text {free }}$ was calculated from $5 \%$ of the diffraction data and monitored throughout refinement. ${ }^{e}$ Outliers observed in regions of poorly defined density.

ment in CNS $\left(R_{\text {work }} / R_{\text {free }}=52 / 53\right)$ of the polyalanine model, a $\sigma$ A-weighted, $2 F_{\mathrm{o}}-F_{\mathrm{c}}$ electron-density map calculated over the full resolution range $(50-1.98 \AA$ ) revealed interpretable side-chain density for a number of conserved residues in the central core of the model.

A noncrystallographic symmetry matrix, assigned with the assumption that the monomer pseudo-2-fold of the $12 \mathrm{~S}$ search model corresponds to an $\alpha \beta$ dimer pseudo-2-fold in the $\mathrm{Sa}$ CT tetramer, was used to calculate an averaged, solvent-flattened electron-density map with DM (40) in CCP4 (41). The map revealed clear side-chain electron density at or near the dimer interface. Automated chain tracing and refinement with ARP-wARP (42) (CCP4) increased the extent of an initial model (from 11 to $80 \%$ of the protein) and resulted in an $R_{\text {work }} / R_{\text {free }}$ of $20 / 26$. After further cycles of model building in $\mathrm{O}(43)$ and refinement in Refmac 5 (CCP4; 44) over the entire resolution range, the final model of $S a$ CT has an $R_{\text {work }} / R_{\text {free }}$ of $18.9 / 21.0$ and consists of $92 \%$ (1120/1224) of the full-length sequence, $2 \mathrm{Zn}^{2+}$, and 583 waters (Table 1). The remaining $8 \%$ of $\mathrm{Sa}$ CT localizes to a 22-residue disordered stretch at the far $\mathrm{N}$ terminus of the $\beta$ subunit and to a 10-residue gap between solvent-exposed helices at the $\mathrm{N}$ terminus of $\alpha$. A simulated annealing composite omit map calculated in CNS and contoured at $1 \sigma$ reveals additional nonprotein electron density in the active site that we tentatively assign to an undetermined portion of the BiSA inhibitor.
A molecular replacement strategy for $E c$ CT was subsequently initiated with a polyalanine search model derived from the refined $\mathrm{Sa}$ CT structure. Dimeric and tetrameric search models were tested in each of several possible hexagonal space groups. A solution [using Molrep (CCP4)] was obtained in $P 6_{5} 22\left(V_{\mathrm{m}}=5.0 \AA^{3} / \mathrm{Da}, 75 \%\right.$ solvent $)$ with the $\alpha \beta$ dimer as a search model (45). In this space group, crystallographic symmetry operators generate the biological heterotetramer from a single $\alpha \beta$ dimer in the asymmetric unit. One cycle of rigid-body, energy-minimization, and simulated-annealing refinement in CNS produced a map with interpretable side-chain density for approximately $80 \%$ of the $E c$ CT primary sequence $\left(R_{\text {work }} / R_{\text {free }}=42 / 46\right)$. In conjunction with model building in $\mathrm{O}$ and overall isotropic $B$-factor refinement in CNS, further cycles of energyminimization and simulated-annealing refinement were conducted until the $R_{\text {free }}$ decreased below $30 \%$. At this stage, seven water molecules were added and a final round of B-group and simulated-annealing refinement was performed (Table 1). The backbone trace of the final Ec CT model $\left(R_{\text {work }} / R_{\text {free }}=25 / 29\right)$ superposes well [root-mean-square deviation $(\mathrm{rmsd})=1 \AA]$ with the $S a$ CT model and lacks density in similar regions of the structure. There are additional poorly defined stretches encompassing residues $88-98$ and $234-238$ of the $\beta$ monomer.

$X$-ray Fluorescence Measurements. Single-crystal and solution-state X-ray fluorescence data were collected at the Protein Crystallography MAD and the Double Crystal Monochromator beamlines, respectively, at the Center for Advanced Microstructures and Devices (Baton Rouge, LA). Fluorescence emission spectra were recorded over an incident energy range of $9640-9680 \mathrm{eV}$ on a single $\mathrm{Sa}$ CT crystal grown as described above and frozen at $100 \mathrm{~K}$ in a cryosolution of $20 \%$ ethylene glycol in mother liquor. Dispersive fluorescence measurements at an excitation energy of $10.5 \mathrm{keV}$ were collected over an emission range of $1-20$ $\mathrm{keV}$ at room temperature on a solution of apo $\mathrm{Sa}$ CT concentrated to $50 \mathrm{mg} / \mathrm{mL}$ in $10 \mathrm{mM}$ HEPES at pH 7.0 and $500 \mathrm{mM} \mathrm{NaCl}$. Spectra were acquired on the empty sample cuvette under identical conditions as a control for background emission from trace elements.

\section{RESULTS AND DISCUSSION}

Overall Fold. The crystal structures of the carboxyltransferase components of acetyl-CoA carboxylase from $\mathrm{Sa}$ and $E c$ were solved to resolutions of 2.0 and $3.2 \AA$, respectively. Both structures confirm the $\alpha_{2} \beta_{2}$ heterotetrameric assembly determined by gel-filtration and sedimentation equilibrium analysis of the purified Ec enzyme (25). The bacterial CT's share $52 \%$ sequence identity, and the tetramers superimpose with a rmsd of $1 \AA$ over $93 \%$ of the backbone trace (unless otherwise noted, the $E c$ residue numbering employed throughout the text refers to residues conserved between both species). The overall structure of the tetramer is a truncated rectangular pyramid with its base at $72 \times 88 \AA$, apex at 23 $\times 34 \AA$, and height at $52 \AA$ (parts a, b, and d of Figure 1). The oligomer is a dimer of dimers related by a 2-fold axis that runs through a central cavity that gradually narrows from a $13 \AA$ diameter opening to a solvent-inaccessible surface at a depth of $23 \AA$. Two distinct interfaces are generated by structurally homologous, wedge-shaped $\alpha$ and $\beta$ monomers that occupy roughly equivalent volumes at the four corners 

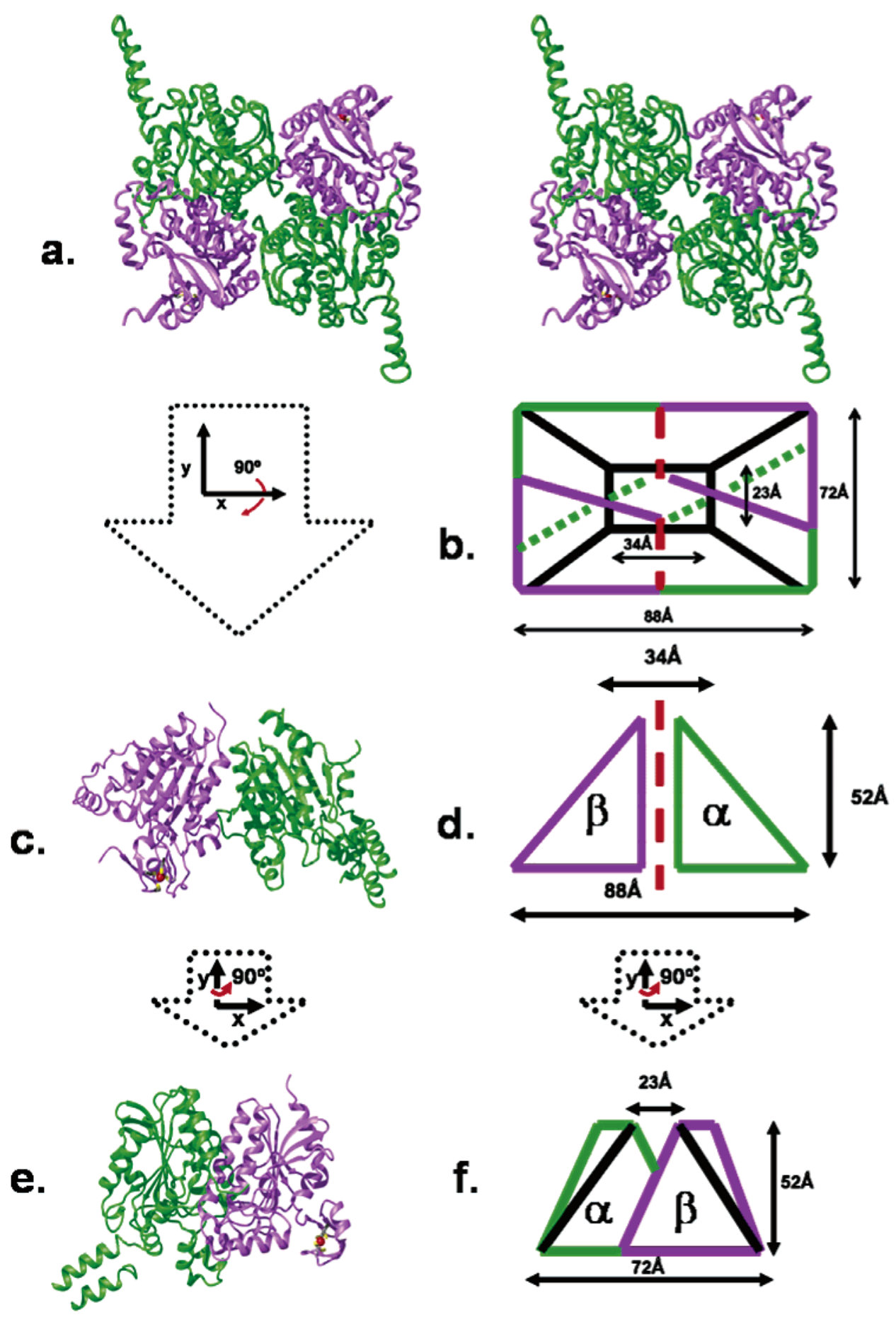

FIGURE 1: Overall fold of $S a$ CT. (a) Stereo ribbon representation of the $\alpha_{2} \beta_{2}$ heterotetramer. The $\alpha$ and $\beta$ monomers are colored in green and purple, respectively. (b) Schematic representation of the $\alpha_{2} \beta_{2}$ heterotetramer in a as a truncated rectangular pyramid viewed from above. The markings - - - and ... indicate the position of the "weak" and "strong" $\alpha \beta$ tetramer interfaces, respectively. The annotation ... also indicates a field out of direct view. (c and d) Perspective along the "weak" $\alpha \beta$ interface in which the tetramer in a and the tetramer schematic in $\mathrm{b}$ have been rotated $90^{\circ}$ about the $x$ axis (see large dotted arrow), respectively. The $\alpha \beta$ dimer, which lies behind this $\alpha \beta$ face has been removed for clarity. (e and f) Perspective along the "strong" $\alpha \beta$ interface in which the tetramer in c and the tetramer schematic in $\mathrm{d}$ has been rotated $90^{\circ}$ about the $y$ axis (see small dotted arrows), respectively. The $\alpha \beta$ dimer, which lies behind this $\alpha \beta$ face has been removed for clarity. a, c, and e were produced in Molmol (46) and rendered in Povray (47). These programs were used to create all ribbon displays presented in this paper.

of the pyramid (parts a and $b$ of Figure 1). The first consists of a "weak" $\alpha \beta$ interface ( 4000 $\AA^{2}$ of buried surface) situated on the vertical plane bisecting the short axes of the pyramid (parts c and d of Figure 1). The second entails a "strong" $\alpha \beta$ interface ( $9000 \AA^{2}$ of buried surface) in which the triangular faces of the monomers are juxtaposed on a $60^{\circ}$ incline (parts e and $f$ of Figure 1).
The structurally similar $\alpha$ and $\beta$ monomers (A and B) possess an $\alpha / \beta$ spiral core composed of a long, twisted, and tapered 7-stranded mixed $\beta$ sheet $(\mathrm{A} \beta 1-5 / \mathrm{B} \beta 5-9, \mathrm{~A} \beta 6 /$ $\mathrm{B} \beta 11$, and $\mathrm{A} \beta 8 / \mathrm{B} \beta 13$ ) orthogonal to a short, 2-stranded parallel $\beta$ platform ( $\mathrm{A} \beta 5 / \mathrm{B} \beta 10$ and $\mathrm{A} \beta 7 / \mathrm{B} \beta 12)$ (Figure 2). The 7-stranded $\beta$ sheet is flanked by helical regions (A $\alpha 12 /$ $\mathrm{B} \alpha 9$ and $\mathrm{A} \alpha 4 / \mathrm{B} \alpha 2$ ) and a 3-helix bundle of $\mathrm{A} \alpha 6 / \mathrm{B} \alpha 4, \mathrm{~A} \alpha 7 /$ 
a.

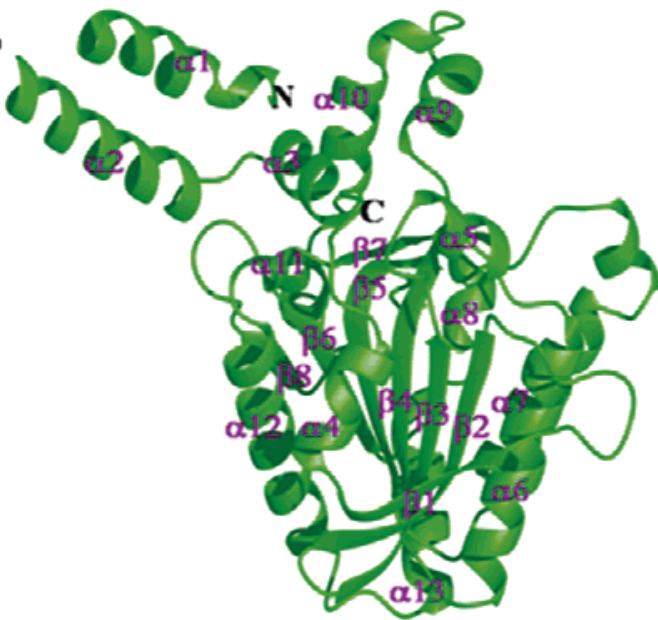

b.

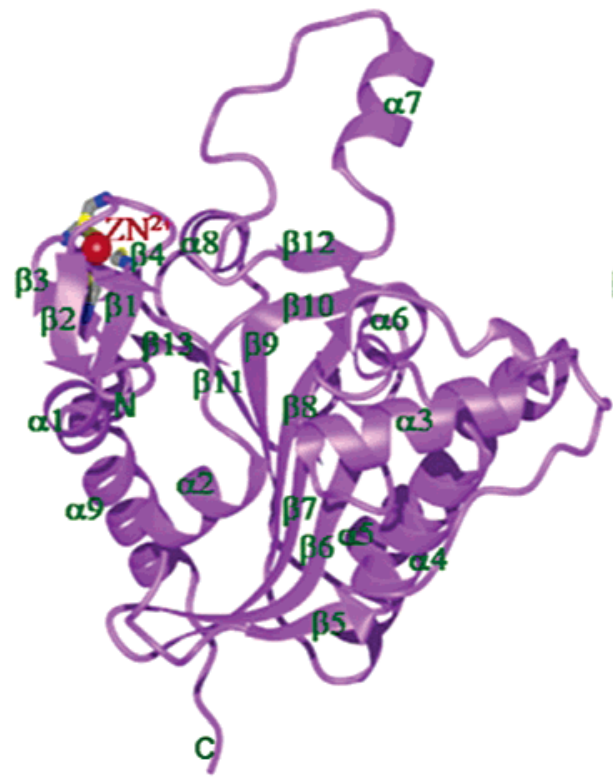

C.

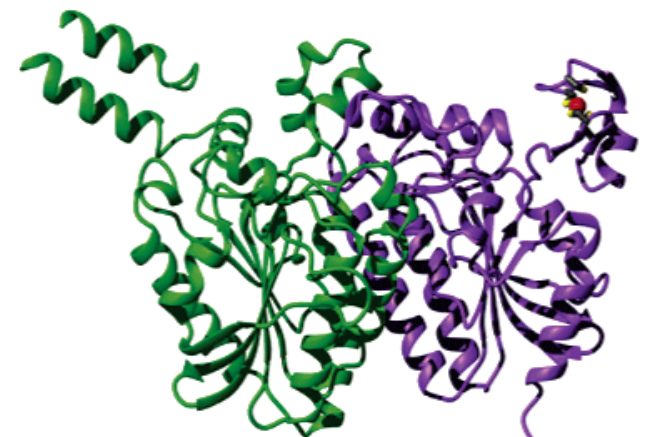

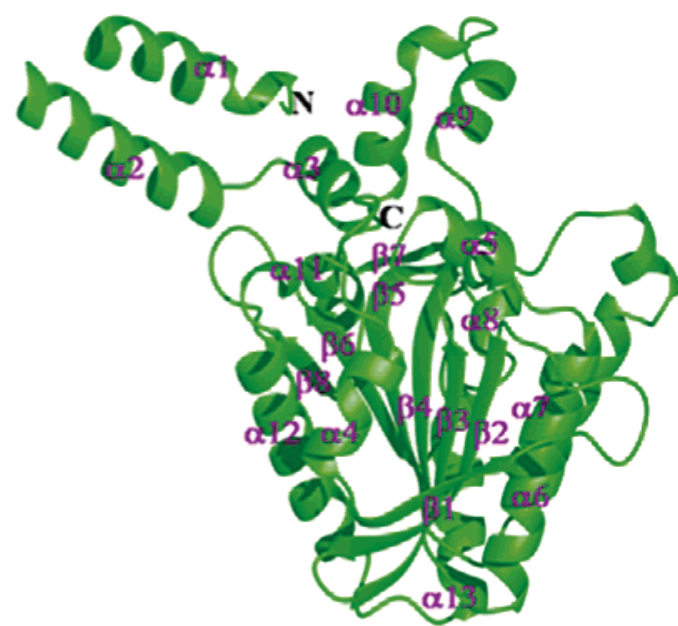
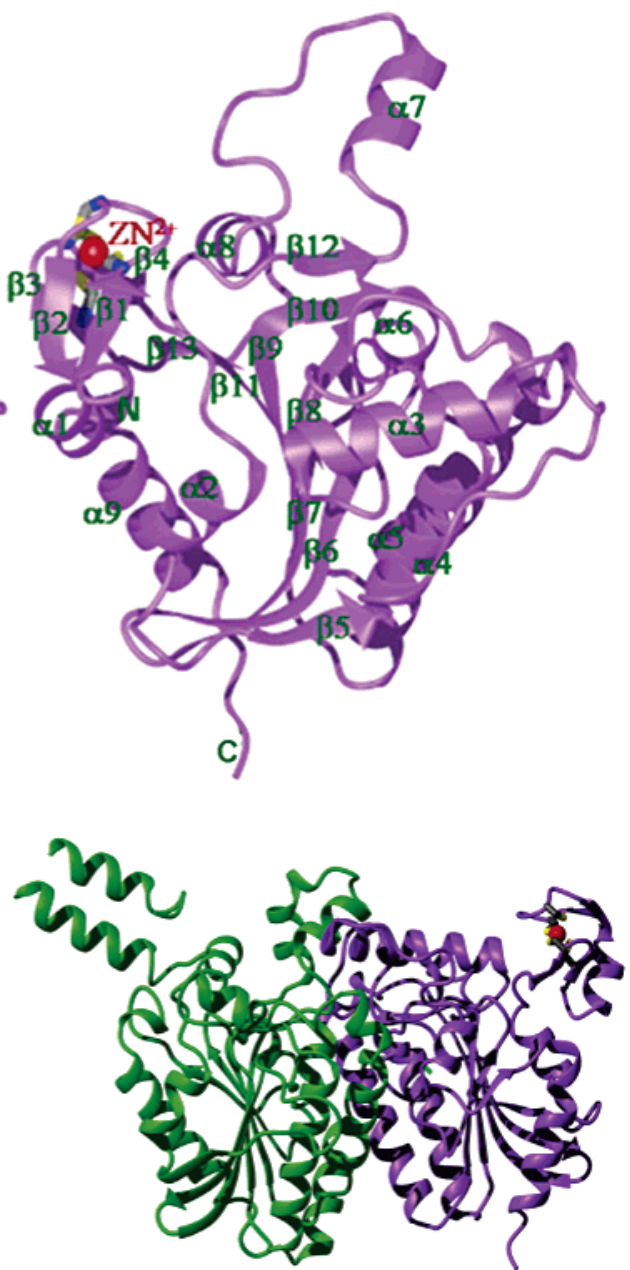

FIGURE 2: Structure of the $\mathrm{Sa}$ CT $\alpha$ and $\beta$ monomers and $\alpha \beta$ dimer. Schematic drawing in stereo of the structure of (a) the $\alpha$ monomer (residues 1-18 and 30-314), (b) the $\beta$ monomer (residues 26-285), and (c) the $\alpha \beta$ dimer. The secondary structural elements are labeled. In the text, these labels are appended with " $\mathrm{A}$ " (representing the $\alpha$ monomer) or "B" (representing the $\beta$ monomer).

$\mathrm{B} \alpha 5$, and $\mathrm{A} \alpha 8 / \mathrm{B} \alpha 6$. These helical elements constitute pseudosymmetrical edges of the triangular face of the wedge. Both sets of helices converge toward the apex of this triangle, and the 3-helix bundle provides the primary scaffold for the 2-stranded platform at its base. The structure-based sequence alignment in Figure 3 highlights (1) the extensive structural homology of the spiral $\alpha / \beta$ monomer fold to enoyl-CoA hydratase (crotonase) and (2) the presence of an oxyanion hole (G204-G205) for CoA-thioenolate stabilization as described for other members of the crotonase superfamily.
Both of these elements, which are maintained through divergent evolution, place the bacterial CT subunits into this enzyme subcategory (26). This classification was originally predicted by Murzin on the basis of sequence alignments (27).

The Active Site. A "ridges in grooves"-type stacking of conserved hydrophobic residues between the A $\alpha 7-8$ (I181, L185, and L209) and Ba5-6 (L174, M177, and A208) helices generates a 6-helix bundle at the "strong" $\alpha \beta$ interface (Figure 4). This packing arrangement orients the triangular 


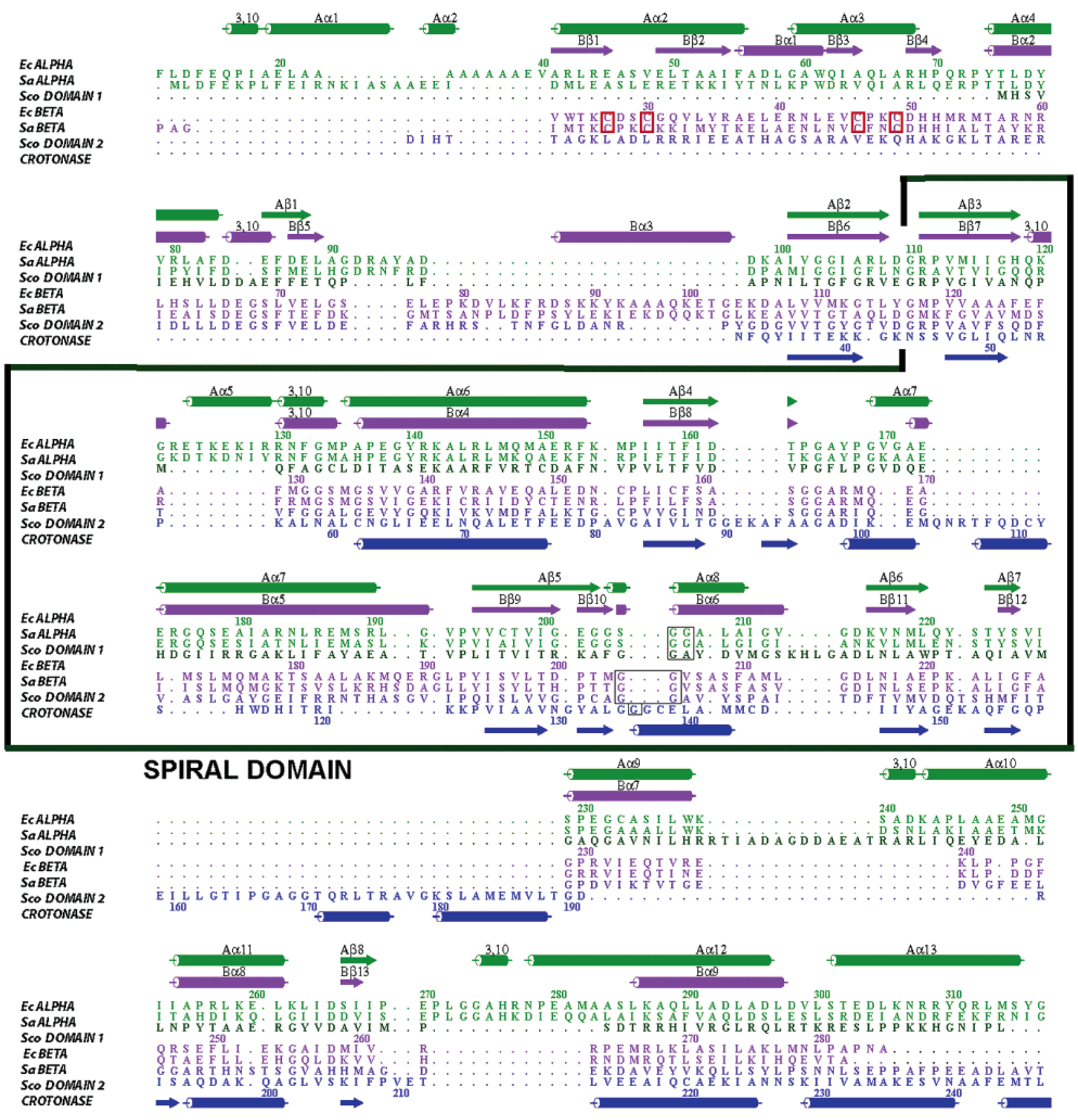

\begin{tabular}{|c|}
\hline $\begin{array}{l}\text { ECALPHA } \\
\text { SaALPHA } \\
\text { ScO DOMAIN } 1 \\
\text { ECBETA } \\
\text { SaBETA } \\
\text { SCO DOMAN } 2 \\
\text { CROTONASE }\end{array}$ \\
\hline
\end{tabular}

FIGURE 3: Structure-based sequence alignment of $E c$ and $S a$ CT $\alpha / \beta$ monomers with Sco CT domains and crotonase. Color coding of sequences: $E c / S a \alpha$ (light green), $S c o$ domain 1 (dark green), $E c / S a \beta$ (light purple), Sco domain 2 (dark purple), and crotonase (blue). Sequences are numbered according to the $E c \alpha / \beta$ monomers, and secondary structural elements corresponding to the $S a \alpha / \beta$ monomers (above the alignment) or crotonase (below the alignment) are color-coded according to the scheme employed for the $S a / E c$ monomer or crotonase sequences. Secondary structural elements within the structurally homologous spiral core domains of $S a / E c$ monomers, and crotonase is surrounded by a bold solid line. Within this outline, residues that constitute the conserved oxyanion holes that recognize the biotin ureido enolate or CoA thioenolate intermediates are boxed in black. The invariant cysteinyl zinc ligands in CT $\beta$ are boxed in red. Residues in $E c$ $\alpha(22-38,41,46$, and 52-53) and $E c \beta$ (93-98 and 285-204) that are not visible or lack clear side-chain density are absent or modeled as alanine, respectively. This figure was produced using STRAP (48) and Alscript (49).

faces of dimer partners on a $60^{\circ}$ tilt with respect to one another and effectively doubles the length of the $\beta$-strand platform by positioning the hairpins from individual mono- mers on opposite sides of a pseudo-2-fold axis (Figure 4). Because conserved residues found on and surrounding this platform are located in the liganded active sites of other 


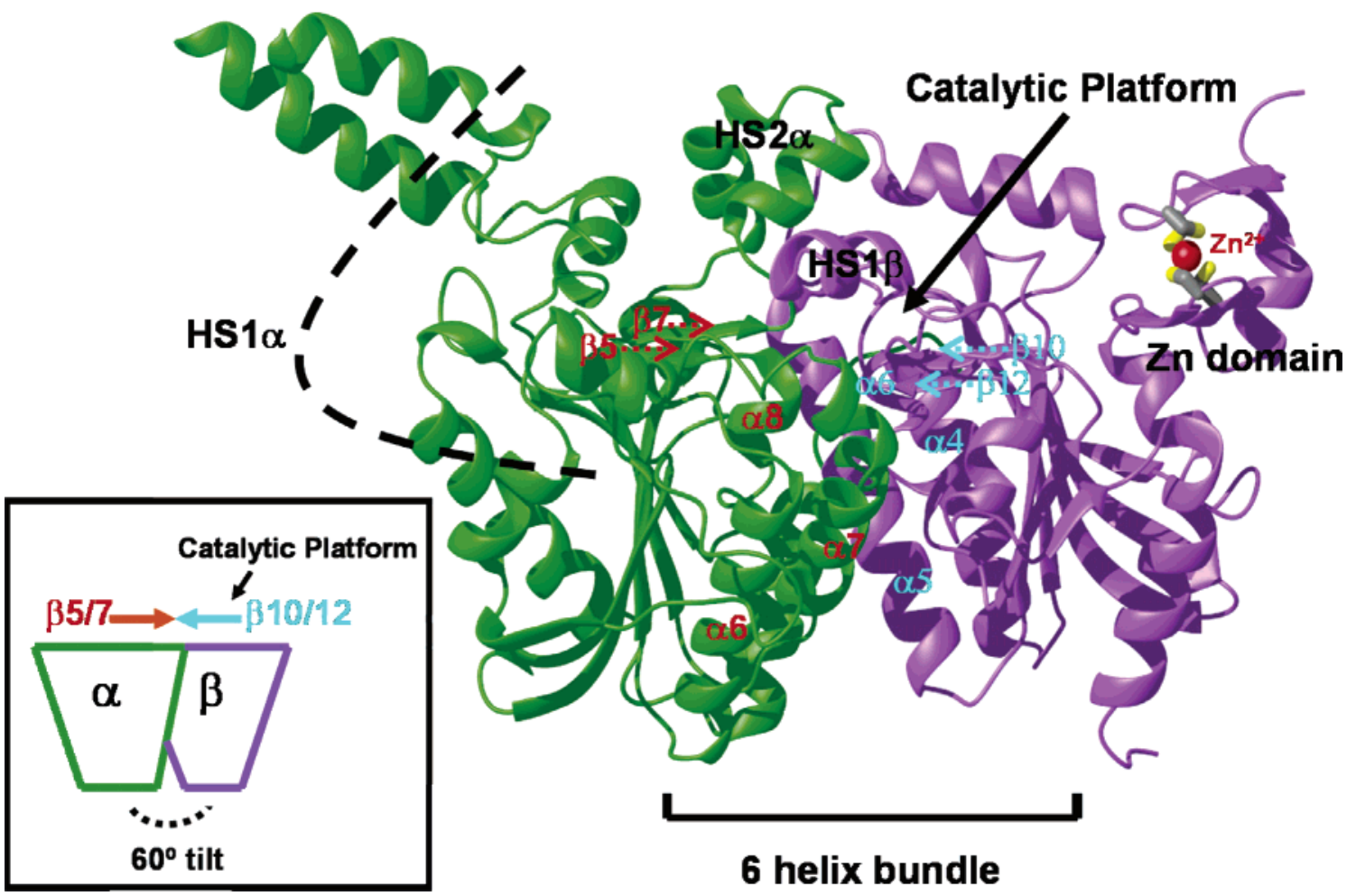

FIGURE 4: Structure of the Sa CT $\alpha \beta$ catalytic dimer. Ribbon representation of the complex between the $\alpha$ (green) and $\beta$ (purple) monomers along the "strong" interface. The pseudo-2-fold equivalent helices or strands that generate the 6 helix bundle or catalytic platform, respectively, are labeled in orange in $\alpha$ and cyan in $\beta$. The annotation - - - indicates the helices encompassed by HS1, and the annotation $\cdots$ indicates the interdomain tilt angle. The inset is a schematic diagram of the ribbon representation.

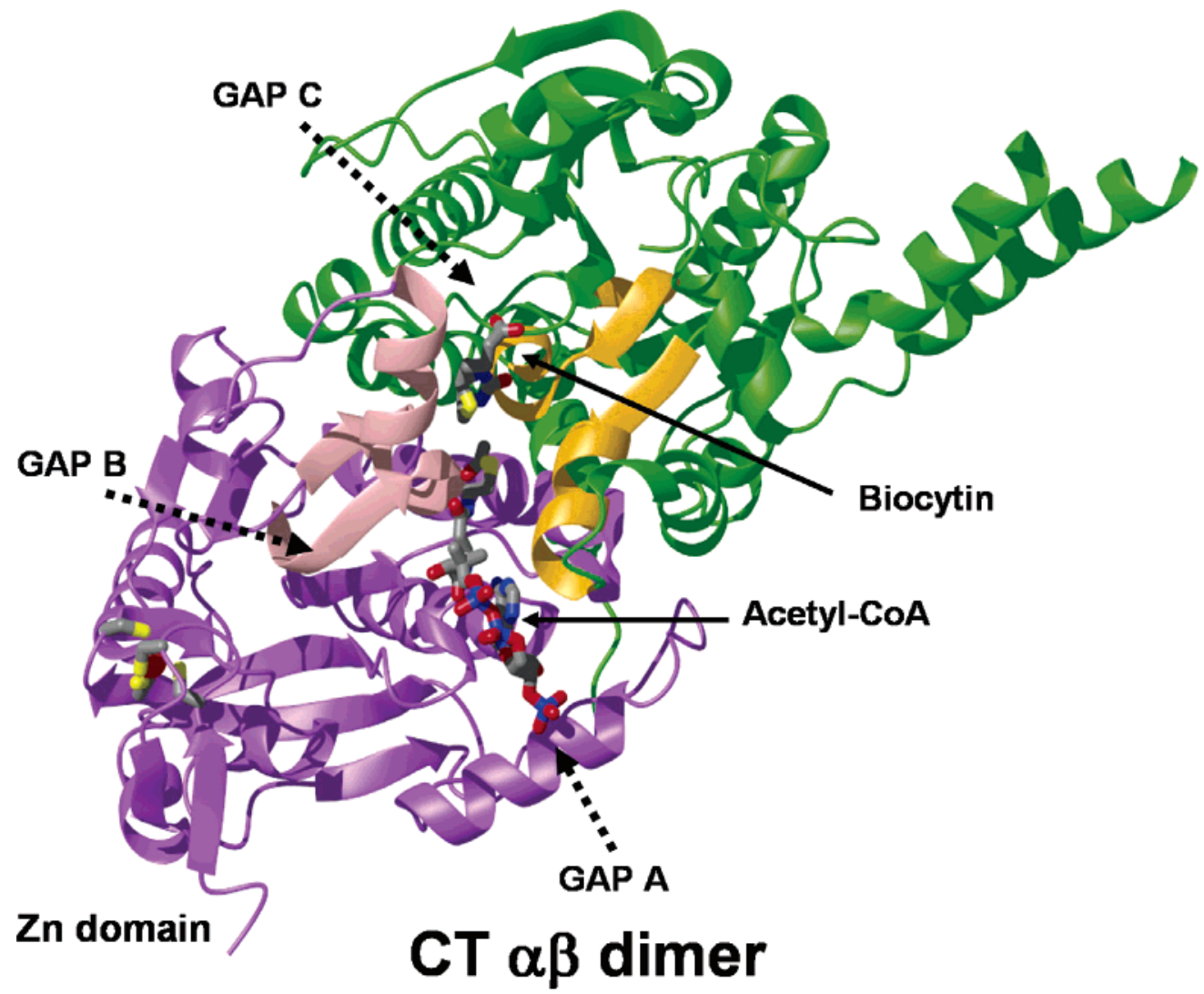

FIGURE 5: Pseudo-2-fold $S a$ CT active-site platform in the $\alpha \beta$ catalytic dimer. The interlocking $\alpha$ (green) and $\beta$ (purple) monomers as viewed from a perspective above the catalytic platform. Centrally located, secondary structural elements that create the pseudo-2-fold through the active site are colored in orange in $\alpha$ and cyan in $\beta$. The acetyl-CoA substrate and biocytin product are modeled in the active site on the basis of the superposition with the Sco CT structure (28). Access/exit routes for substrates/products in the CT reaction are labeled as GAPS A, B, and C. 


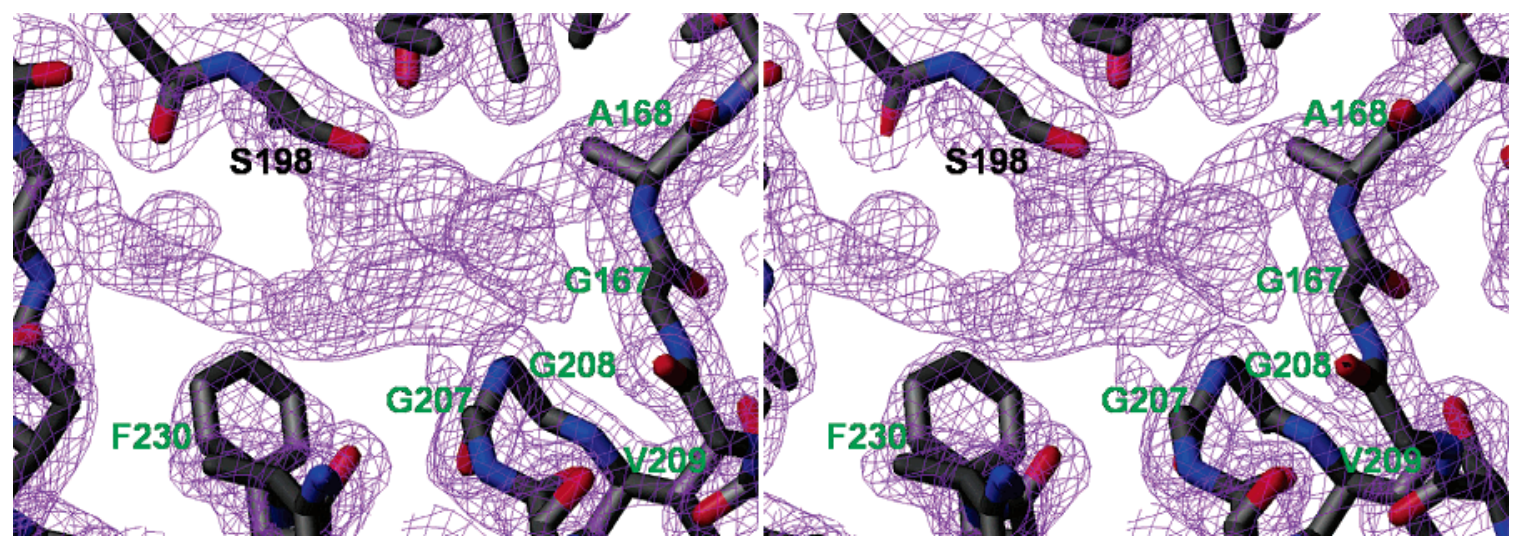

FIGURE 6: $S a$ CT active site. A stereo representation of a composite omit $2 F_{\mathrm{o}}-F_{\mathrm{c}}$ electron-density map (violet) contoured at $1 \sigma$ and calculated for the refined $S a \mathrm{CT}$ model in the region of the central pseudo-2-fold of the active site. Residue labels corresponding to amino acids from $S a$ CT $\alpha$ and $\beta$ are colored black and green, respectively. Centrally positioned, nonprotein electron density ascribed to BiSA is proposed to interfere with acetyl-CoA access to the G207-G208 oxyanion hole of CT $\beta$.
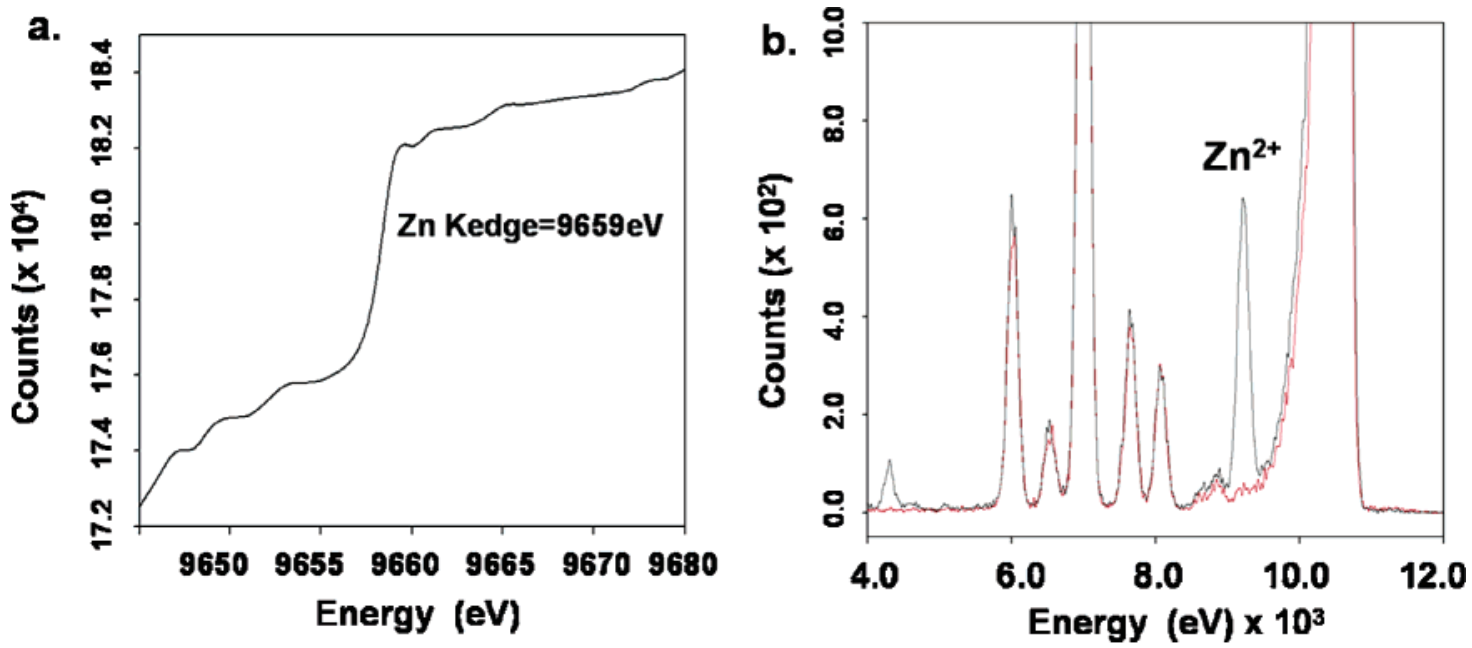

c.
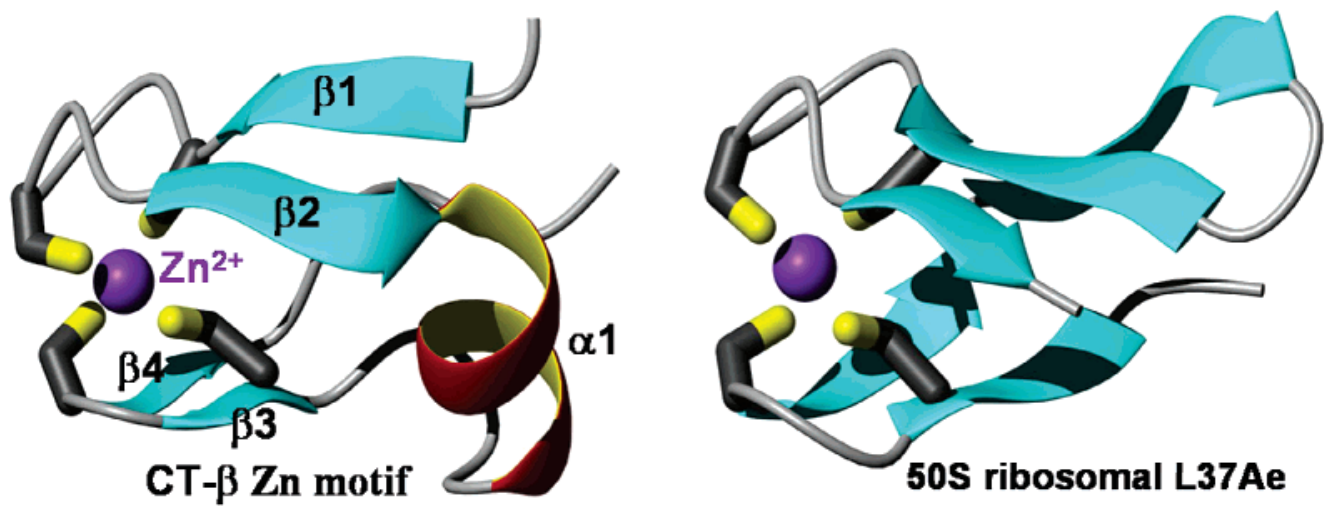

FIGURE 7: $S a$ CT binds zinc with an atypical zinc ribbon motif. (a) X-ray fluorescence scan of a single $S a$ CT crystal reveals the characteristic Zn K-edge profile. (b) Dispersive X-ray fluorescence spectra of a cuvette blank (red solid line) and solution-state $S a$ CT as purified (black solid line) show a clear peak at the Zn K-edge. (c) Side-by-side ribbon representations of the Zn ribbon motif of Sa CT- $\beta$ and the "classical" $\mathrm{Zn}$ ribbon from the 50S ribosomal protein L37Ae of the halophilic archaebacterium Haloarcula marismortui.

biotin-dependent carboxylases, including the substrate-binding clefts of Streptomyces coelicolor (Sco)/Saccharomyces cerevisiae $(\mathrm{Sc}) \mathrm{CT}(23,28)$ and Propionibacterium shermanii 12S transcarboxylase (Ps 12S) (29), we will henceforth refer to this site as the "catalytic platform" (Figure 4).

The structurally equivalent overall folds of the $\alpha$ and $\beta$ subunits suggest duplication and divergence of a single ancestral CT subunit gene. However, an inherent asymmetry in the structural homology of the $\alpha$ and $\beta$ subunits allows for the creation of distinct biotin and acetyl-CoA-specific subsites. When viewed from a perspective above the $\alpha \beta$ interface, the $\alpha$ and $\beta$ subunits possess structurally disparate motifs that project toward the viewer. As shown in Figure 4 , four subdomains [ 2 helical domains from the $\alpha$ subunit (designated helical subdomain (HS) $1 \alpha$ and $2 \alpha$ (HS $1 \alpha$ and HS2 $\alpha$ ) and a Zn-binding domain and helical domain from the $\beta$ monomer (HS1 $\beta$ )] coalesce to provide a canopy over the catalytic platform where three portals (labeled gaps A, $\mathrm{B}$, and $\mathrm{C}$ in Figure 5) in the canopy appear to provide activesite access. The regions that flank these portals break the symmetry of the active site that would result if the structural homology of the $\alpha$ or $\beta$ subunits extended over the entire 


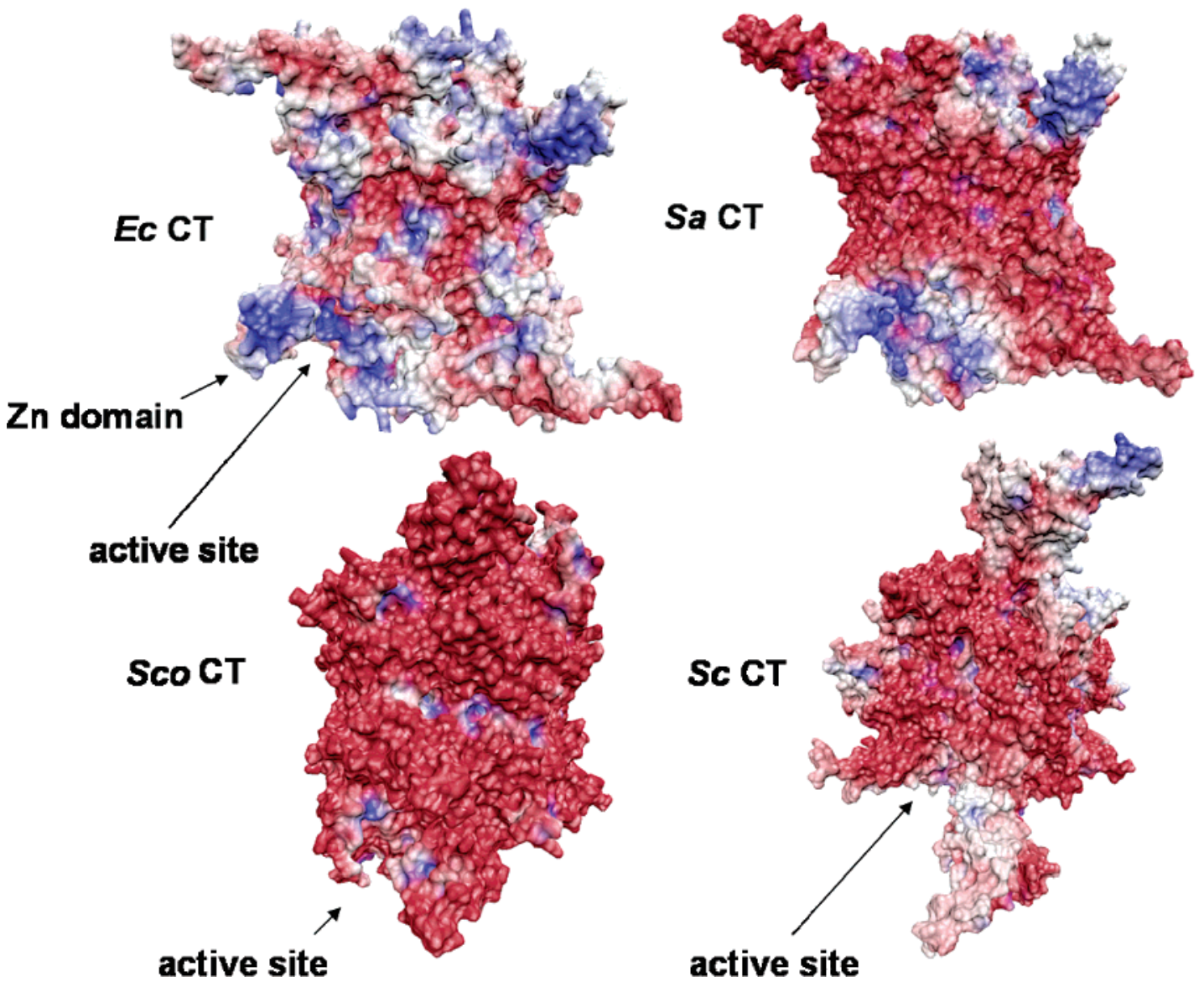

FIGURE 8: Sa/Ec CT active site presents a markedly electropositive surface by comparison to other CT structures. Electrostatic surface renderings for the $S a / E c$ CT tetramers and the $S c o / S c$ CT dimers are contoured from -5 (red) to 0 (white) to +5 (blue) kT/E. Only one of the two pseudosymmetrically related active sites is indicated for each structure. Electrostatic potentials were calculated using Grasp (50) and surface-mapped and rendered in VMD (51).

protein. The portals may serve as "traffic control" elements that coordinate active-site access for substrates constrained by bulky carrier groups: biotinoyl carboxyl carrier protein and coenzyme A.

Two key conserved residues in the active site, G206 and G207, are located in the consensus sequence 206-GGXXHHH-212 (where $\mathrm{X}=$ a small residue, $\mathrm{H}=$ hydrophobic), which is at the $\mathrm{N}$ terminus of $\mathrm{A} \alpha 8$ (Figure 3). The peptidic hydrogens of G206 and G207 form a conserved oxyanion hole at the base of this helix that is proposed to stabilize a ureido enolate that forms during decarboxylation of carboxybiotin $\mathrm{N} 1$ in the homologous $\mathrm{CT}$ subunit of propionylCoA carboxylase (PCC) from Sco (28). Similarly, a conserved oxyanion hole in the $\beta$ subunit is formed by G204 and $\mathrm{G} 205$ at the $\mathrm{N}$ terminus of $\mathrm{B} \alpha 6$ (Figure 3). The peptidic hydrogens of this glycine pair in the Sco PCC structure, which correspond to the conserved oxyanion hole in crotonase, were found to act as hydrogen-bond donors to the carbonyl of the methyl-malonyl-CoA (MMCoA) ligand and proposed to stabilize the developing negative charge on the enolate intermediate (28).

It is important to note that $S a \mathrm{CT}$ was crystallized in the presence of a BiSA inhibitor that combines features of both substrates: coenzyme A is covalently linked to carboxybiotin (19). However, continuous electron density consistent with the intact inhibitor is not apparent (Figure 6). This absence of density could be a consequence of hydrolysis of the analogue in the course of the crystallization or could simply reflect a lack of specific contacts over the length of the inhibitor in our crystallization conditions. Inspection of a $2 F_{\mathrm{o}}$ $-F_{\mathrm{c}}$ composite omit map reveals nonprotein density that likely corresponds to a portion of the inhibitor in a hydrophobic region of the active site at the central pseudo2 -fold of the catalytic platform (Figure 6). In the structure of MMCoA/biocytin-bound Sco PCC, a biotin-dependent carboxyltransferase whose acyl-CoA substrate differs from acetyl-CoA by the addition of a methyl group, the position of the acyl thioester of MMCoA is in close proximity to the density that we tentatively attribute to the BiSA inhibitor. This density predominantly covers the hydrophobic cavity that presents the helical dipole and oxyanion hole (G207G208 of B $\alpha 6$ in $S a$ CT) to the acyl thioester of MMCoA. Mutations in $S a$ or $E c$ CT that confer resistance to the pyrollidine dione derivative CPD2 (16) localize to two highly conserved residues that are either nearby (G203A in $\mathrm{Sa} \mathrm{CT} \alpha$ ) or within ( $\mathrm{S} 207 \mathrm{Y}$ in $E c \mathrm{CT} \beta$ ) consensus sequences that define this oxyanion hole.

The Zn Domain: A Unique Feature of the Prokaryotic Enzyme. While the overall fold of bacterial CT confirms that it is indeed a member of the crotonase superfamily, a surprising and novel feature of the enzyme is the $\mathrm{Zn}$ domain (Figure 7c). Early $F_{\mathrm{o}}-F_{\mathrm{c}}$ maps calculated for the $S a$ CT structure revealed a $20 \sigma$ peak encapsulated by a tetrahedral arrangement of sulfurs contributed by the cysteine residues that terminate $\mathrm{B} \beta 1(\mathrm{C} 27) / \mathrm{B} \beta 3(\mathrm{C} 46)$ and those immediately preceding $\mathrm{B} \beta 2(\mathrm{C} 30) / \mathrm{B} \beta 4(\mathrm{C} 49)$ (Figure 3$)$. X-ray fluores- 
cence spectra collected on solution-state and crystalline preparations of $S a \mathrm{CT}$ in its apo form demonstrate that the peak corresponds to $\mathrm{Zn}^{2+}$ (parts a and $\mathrm{b}$ of Figure 7). Sequence alignment of the CT $\beta$ primary sequence with orthologous enzymes from eubacteria, algae, plants, and animals reveals that the cysteine ligands are invariant residues within an independent $\mathrm{N}$-terminal domain that exists in prokaryotic but not eukaryotic $\mathrm{CT}$. The $\mathrm{Zn}$ motif in $\mathrm{CT} \beta$ is an atypical Cys4 "zinc ribbon" that most closely resembles the Zn-binding structures observed in ribosomal proteins (Figure 7c; PDB code 1jj2), RNA polymerase II subunits (1i5b) and the basal transcription factors TFIIS(1tfi) and TFIIB(1pft). Unlike the classical motif in which the second sheet is three-stranded and significantly longer than the first (30), the fold in CT $\beta$ bears an intervening helix between two short $\beta$ hairpins (Figure 7c).

The inner face of the CT $\beta$ Zn-binding domain forms roughly half of an electropositive, hemicircular surface that encompasses residues from both subunits (Figure 8). A comparison of the electrostatic properties of $E c / S a$ CT with the structurally homologous carboxyltransferases $S c \mathrm{CT}$ and $S c o$ PCCB reveals that $E c / S a$ CT possess a greater overall net positive charge at $\mathrm{pH} 7(E c \mathrm{CT}=+4, S a \mathrm{CT}=-16, S c$ $\mathrm{CT}=-26$, and $S c o \mathrm{CT}=-42$ ). Zn domains are commonly associated with DNA-binding proteins, and preliminary studies using electrophoretic mobility shift assays indicate that $E c$ CT does indeed bind DNA (data not shown). Studies to determine the DNA-binding specificity of $E c \mathrm{CT}$, if any, are underway.

In addition to nucleic-acid-binding functions, $\mathrm{Zn}$ ribbon structures have also been found to constitute catalytically essential, active-site "lids" in isoleucyl-tRNA synthetase, methionyl-tRNA synthetase, and the histone deacetylase silent information regulator $2(31-35)$. In this regard, it is noteworthy that the $\beta$ subunit of the prokaryotic $\alpha_{2} \beta_{2}$ CT heterotetramer isolated from plant chloroplast, which aligns over the primary sequence of both bacterial CT subunits (39\%/47\% identity between pea and $E c$ CT- $\beta / \alpha$ ), bears the zinc finger consensus $\mathrm{C}-\mathrm{X}_{2}-\mathrm{C}-\mathrm{X}_{15}-\mathrm{C}-\mathrm{X}_{2}-\mathrm{C}$ (35). Deletion of the $\mathrm{Zn}$ finger motif in plastidic CT completely abrogates enzymatic activity, while mutagenesis of the four individual cysteines to alanine produces an enzyme that exhibits $<20 \%$ wild-type activity (36). Because phylogenetic evidence indicates that plastidic ACC subunit genes are derived from a cyanobacterial endosymbiont and the site of plant lipid biosynthesis resides within the choroplast, these observations suggest the possibility that the prokaryotic CT $\mathrm{Zn}$ domain participates in a conserved activity related to fatty acid synthesis initiation (37).

\section{ACKNOWLEDGMENT}

We thank Steve VanderRoest (Pfizer Global Research and Development, MI) for his technical contribution. We also thank Christopher Bianchetti and the late Roland Tittsworth for assistance in the collection of X-ray fluorescence data at the Double Crystal Monochromator Beamline at the Center for Advanced Microstructures and Devices, LA. The IMCACAT beamline 17-ID at the Advanced Photon Source was supported by the companies of the Industrial Macromolecular Crystallography Association through a contract with the Illinois Institute of Technology. Use of the Advanced Photon
Source was supported by the U.S. Department of Energy, Office of Science, Office of Basic Energy Sciences, under contract number W-31-109-Eng-38.

\section{REFERENCES}

1. CDC (2004) National Nosocomial Infections Surveillance (NNIS) report, data summary from January 1992-June 2004, issued October 2004.

2. Menichetti, F. (2005) Current and emerging serious Gram-positive infections, Clin. Microbiol. Infect. 11, supplement 3, 22-28.

3. CDC (2004) Brief report: Vancomycin-resistant Staphylococcus aureus, New York, MMWR 53, 322-323.

4. CDC (2002) Vancomycin-resistant Staphylococcus aureus, Pennsylvania, MMWR 51, 902

5. CDC (2002) Staphylococcus aureus resistant to vancomycin, United States, MMWR 51, 565-567.

6. Shah, P. M. (2005) The need for new therapeutic agents: What is the pipeline? Clin. Microbiol. Infect. 11, supplement 3, 3642.

7. Marrakchi, H., Zhang, Y. M., and Rock, C. O. (2002) Mechanistic diversity and regulation of Type II fatty acid synthesis, Biochem. Soc. Trans. 30, 1050-1055.

8. Heath, R. J., White, S. W., and Rock, C. O. (2001) Lipid biosynthesis as a target for antibacterial agents. Prog. Lipid Res. 40, 467-497.

9. Campbell, J. W., and Cronan, J. E., Jr. (2001) Bacterial fatty acid biosynthesis: Targets for antibacterial drug discovery, Annu. Rev. Microbiol. 55, 305-332.

10. Heath, R. J., Yu, Y. T., Shapiro, M. A., Olson, E., and Rock, C. O. (1998) Broad spectrum antimicrobial biocides target the FabI component of fatty acid synthesis, J. Biol. Chem. 273, 3031630320.

11. Banerjee, A., et al. (1994) inhA, a gene encoding a target for isoniazid and ethionamide in Mycobacterium tuberculosis, Science $263,227-230$.

12. Vance, D., Goldberg, I., Mitsuhashi, O., and Bloch, K. (1972) Inhibition of fatty acid synthetases by the antibiotic cerulenin, Biochem. Biophys. Res. Commun. 48, 649-656.

13. D’Agnolo, G., Rosenfeld, I. S., Awaya, J., Omura, S., and Vagelos, P. R. (1973) Inhibition of fatty acid synthesis by the antibiotic cerulenin. Specific inactivation of $\beta$-ketoacyl-acyl carrier protein synthetase, Biochim. Biophys. Acta 326, 155-156.

14. Hayashi, T., Yamamoto, O., Sasaki, H., Kawaguchi, A., and Okazaki, H. (1983) Mechanism of action of the antibiotic thiolactomycin inhibition of fatty acid synthesis of Escherichia coli, Biochem. Biophys. Res. Commun. 115, 1108-1113.

15. Hayashi, T., Yamamoto, O., Sasaki, H., Okazaki, H., and Kawaguchi, A. (1984) Inhibition of fatty acid synthesis by the antibiotic thiolactomycin, J. Antibiot. 37, 1456-1461.

16. Freiberg, C., et al. (2004) Identification and characterization of the first class of potent bacterial acetyl-CoA carboxylase inhibitors with antibacterial activity, J. Biol. Chem. 279, 26066-26073.

17. Pohlmann, J., et al. (2005) Pyrrolidinedione derivatives as antibacterial agents with a novel mode of action, Bioorg. Med. Chem. Lett. 15, 1189-1192.

18. Zagnitko, O., Jelenska, J., Tevzadze, G., Haselkorn, R., and Gornicki, P. (2001) An isoleucine/leucine residue in the carboxyltransferase domain of acetyl-CoA carboxylase is critical for interaction with aryloxyphenoxypropionate and cyclohexanedione inhibitors, Proc. Natl. Acad. Sci. U.S.A. 98, 6617-6622.

19. Levert, K. L., and Waldrop, G. L. (2002) A bisubstrate analog inhibitor of the carboxyltransferase component of acetyl-CoA carboxylase, Biochem. Biophys. Res. Commun. 291, 1213-1217.

20. Cronan, J. E., Jr., and Waldrop, G. L. (2002) Multi-subunit acetylCoA carboxylases, Prog. Lipid Res. 41, 407-435.

21. Barber, M. C., Price, N. T., and Travers, M. T. (2005) Structure and regulation of acetyl-CoA carboxylase genes of metazoa, Biochim. Biophys. Acta 1733, 1-28.

22. Jitrapakdee, S., and Wallace, J. C. (2003) The biotin enzyme family: Conserved structural motifs and domain rearrangements, Curr. Protein Pept. Sci. 4, 217-229.

23. Zhang, H., Yang, Z., Shen, Y., and Tong, L. (2003) Crystal structure of the carboxyltransferase domain of acetyl-coenzyme A carboxylase, Science 299, 2064-2067.

24. Blanchard, C. Z., and Waldrop, G. L. (1998) Overexpression and kinetic characterization of the carboxyltransferase component of acetyl-CoA carboxylase, J. Biol. Chem. 273, 9140-9145. 
25. Guchhait, R. B., et al. (1974) Acetyl coenzyme A carboxylase system of Escherichia coli. Purification and properties of the biotin carboxylase, carboxyltransferase, and carboxyl carrier protein components, J. Biol. Chem. 249, 6633-6645.

26. Gerlt, J. A., and Babbitt, P. C. (2001) Divergent evolution of enzymatic function: Mechanistically diverse superfamilies and functionally distinct suprafamilies, Annu. Rev. Biochem. 70, 209246.

27. Murzin, A. G. (1998) How far divergent evolution goes in proteins, Curr. Opin. Struct. Biol. 8, 380-387.

28. Diacovich, L., et al. (2004) Crystal structure of the $\beta$-subunit of acyl-CoA carboxylase: Structure-based engineering of substrate specificity, Biochemistry 43, 14027-14036.

29. Hall, P. R., et al. (2003) Transcarboxylase $12 \mathrm{~S}$ crystal structure: Hexamer assembly and substrate binding to a multienzyme core, EMBO J. 22, 2334-2347.

30. Krishna, S. S., Majumdar, I., and Grishin, N. V. (2003) Structural classification of zinc fingers: Survey and summary, Nucleic Acids Res. 31, 532-550.

31. Crepin, T., Schmitt, E., Blanquet, S., and Mechulam, Y. (2004) Three-dimensional structure of methionyl-tRNA synthetase from Pyrococcus abyssi, Biochemistry 43, 2635-2644.

32. Serre, L., et al. (2001) How methionyl-tRNA synthetase creates its amino acid recognition pocket upon L-methionine binding, $J$. Mol. Biol. 306, 863-876.

33. Glasfeld, E., and Schimmel, P. (1997) Zinc-dependent tRNA binding by a peptide element within a tRNA synthetase, Biochemistry 36, 6739-6744.

34. Sherman, J. M., et al. (1999) The conserved core of a human SIR2 homologue functions in yeast silencing, Mol. Biol. Cell 10, 30453059.

35. Zhao, K., Chai, X., and Marmorstein, R. (2004) Structure and substrate binding properties of cobB, a Sir2 homolog protein deacetylase from Escherichia coli, J. Mol. Biol. 337, 731-741.

36. Kozaki, A., Mayumi, K., and Sasaki, Y. (2001) Thiol-disulfide exchange between nuclear-encoded and chloroplast-encoded subunits of pea acetyl-CoA carboxylase, J. Biol. Chem. 276, 3991939925.

37. Martin, W. B., et al. (1998). Gene transfer to the nucleus and the evolution of chloroplasts, Nature 393, 162-165.
38. Otwinowski, Z., and Minor, W. (1997) Processing of X-ray diffraction data collected in oscillation mode, Methods Enzymol. 276, 307-326.

39. Brunger, A. T., et al. (1998) Crystallography and NMR system: A new software suite for macromolecular structure determination, Acta Crystallogr., Sect. D: Biol. Crystallogr. 54 (part 5), 905921.

40. Cowtan, K. (1994) Joint CCP4 and ESF-EACBM Newsletter on Protein Crystallography 31, 34-38.

41. Collaborative Computational Project, Number 4 (1994) The CCP4 suite: Programs for protein crystallography, Acta Crystallogr., Sect. D: Biol. Crystallogr. 57, 760-763.

42. Perrakis, A., Harkiolaki, M., Wilson, K. S., and Lamzin, V. S. (2001) ARP/wARP and molecular replacement, Acta Crystallogr., Sect. D: Biol. Crystallogr. 57, 1445-1450.

43. Jones, T. A., Zou, J. Y., Cowan, S. W., and Kjeldgaard, M. (1991) Improved methods for building protein models in electron density maps and the location of errors in these models, Acta Crystallogr., Sect. A: Found. Crystallogr. 47 (part 2), 110-119.

44. Murshudov, G. N., Vagin, A. A., and Dodson, E. J. (1997) Refinement of macromolecular structures by the maximumlikelihood method, Acta Crystallogr., Sect. D: Biol. Crystallogr. $53,240-255$.

45. Vagin, A. A., and Teplyakov, A. (1997) MOLREP: An automated program for molecular replacement, J. Appl. Crystallogr. 30, $1022-1025$.

46. Koradi, R., Billeter, M., and Wüthrich, K. (1996) MOLMOL: A program for display and analysis of macromolecular structures, J. Mol. Graphics 14, 51-55.

47. POVRAY, http:/www.povray.org/.

48. Gille, C., and Frommel, C. (2001) STRAP: Editor for structural alignments of proteins, Bioinformatics 17, 377-378.

49. Barton, G. J. (1993) ALSCRIPT: A tool to format multiple sequence alignments, Protein Eng. 6, 37-40.

50. Nicholls A., Sharp K., and Honig B. (1991) Proteins: Struct., Funct., Genet. 11, $281 \mathrm{ff}$.

51. Humphrey, W., Dalke, A., and Schulten, K. (1996) VMD-Visual molecular dynamics, J. Mol. Graphics 14, 33-38.

BI0520479 